\title{
Evaluation of the upper respiratory tract in the horse during treadmill exercise - A review Part I: Endoscopy
}

\author{
Sabine B. R. Kästner ${ }^{1}$, M. A. Weishaupt ${ }^{1}$ and H.G.G Townsend ${ }^{2}$ \\ 1 Veterinär-Chirurgische Klinik der Universität Zürich, Zürich, Schweiz \\ ${ }^{2}$ Department of Veterinary Internal Medicine, Western College of Veterinary Medicine, University of Saskatchewan, Canada
}

\begin{abstract}
Summary
Literature pertaining to the evaluation of the upper respiratory tract of the horse during exercise was reviewed. Articles were found by searching two databases. Videoendoscopy, upper airway pressure measurement and airflow measurements are used for assessing upper airway function. Treadmill accomodation and exercise protocols, examination protocols, the endoscopy technique, indications for the examination during exercise and normal and abnormal functions of the upper airways are described in part I of this review. The most frequently observed dysfunctions are dorsal displacement of the soft palate with an incidence of 21 to $52 \%$ and laryngeal hemiplegia with an incidence of 9 to $25 \%$ of all upper airway obstructions. Videoendoscopy during treadmill exercise as a subjective technique can already accomplish a good evaluation of the upper airway function. But a final assessment of the presence of a respiratory limitation can only be made by the quantitative determination of upper airway flow mechanics (airway pressure and flow-volume measurement) which are presented in part II of this review.
\end{abstract}

keywords: $\quad$ horse, endoscopy, upper airway, treadmill, exercise

\section{Beurteilung der oberen Luftwege des Pferdes während der Belastung auf einem Laufband - Eine Literaturstudie Teil I: Endoskopie}

Die vorliegende Literaturstudie beschäftigt sich mit der Untersuchung der oberen Atemwege des Pferdes unter Belastung auf einem Laufband. Im vorliegenden ersten Teil wird die Belastungsendoskopie beschrieben. Die Literaturdatenbanken Index Medicus (Medline) und Commonwealth Agricultural Bureaux (CAB) wurden nach den Begriffen "horse“ or "equine" und "treadmill" abgefragt. Die Artikel, welche die oberen Atemwege betrafen wurden manuell ausgewählt. Die Abfrage erfolgte für den Zeitraum von „1966 bis heute."

Die Ventilation ist ein wichtiger, limitierender Faktor für die Leistungsfähigkeit des Pferdes. Erkrankungen des Respirationstraktes sind die zweithäufigste Ursache für Leistungsverlust beim Pferd. Weitergehende diagnostische Methoden, wie die Untersuchung auf einem Laufband können deshalb bei der Früherkennung oder bei Klärung der funktionellen Bedeutung einer Erkrankung eine wichtige Rolle spielen. Untersuchungen zur Atmungsmechanik haben gezeigt, dass eine endoskopisch sichtbare Abnormalität der oberen Luftwege nicht unbedingt zu einer klinisch bedeutsamen Beeinträchtigung der Atmung führen muss. Andererseits schliesst das Fehlen einer Veränderung in Ruhe eine funktionelle Störung unter Belastung nicht aus.

Die Anforderungen an das Laufband, Voruntersuchungsprótokolle und Indikationen für die Untersuchung unter Belastung werden beschrieben. Desweiteren werden der Angewöhnungsprozess des Pferdes an das Laufband, die verschiedenen Belastungsprotokolle und die Technik der Belastungsendoskopie dargestellt.

Die häufigsten Dysfunktionen der oberen Luftwege unter Belastung sind die Hemiplegia laryngis mit einer Häufigkeit von $9 \%$ bis $25 \%$ und die Dorsalverlagerung des Gaumensegels (DDSP) mit einer Inzidenz von $21 \%$ bis $52 \%$ aller Fehlfunktionen der oberen Atemwege. Weiter können eine Vielzahl anderer, seltener Fehlfunktionen verschiedenster Strukturen des Pharynx und Larynx beobachtet werden wie, intermittierendes Entrapment der Epiglottis, Epiglottisretroversion, Flattern oder Vorfall der Aryepiglottisfalten, Stimmbandflattern, Stimmbandvorfall (ohne Hemiplegia laryngis) und Kollaps des Nasopharynx. Bei 17,7\% bis $26 \%$ von Pferden mit dem Vorbericht Leistungsverlust konnte eine funktionelle Störung unter Belastung diagnostiziert werden. Liegt zudem ein abnormales Atemgeräusch vor oder können „verdächtige“ Veränderungen bei der Ruheendoskopie beobachtet werden erhöht sich diese Häufigkeit auf $32 \%$ bis $92 \%$. Andererseits konnten bei $61 \%$ der Pferde, welche belastungsendoskopiert wurden, die Diagnose bereits nach der Ruheendoskopie gestellt werden. Dies zeigt die Bedeutung einer sorgfältigen klinischen Untersuchung vor einer Untersuchung auf dem Laufband. Mit der Belastungsendoskopie kann bereits eine sehr gute subjektive Beurteilung der Funktion der oberen Atemwege erreicht werden. Das Vorliegen einer Behinderung der Atmung kann jedoch nur mit den objektiven Methoden Druck- und Atemstromstärkemessungen dokumentiert werden. Diese Methoden werden im Teil II dieser Literaturstudie beschrieben. Eine Kombination der verschiedenen Methoden gilt als das derzeitige Optimum zur Beurteilung der Funktion der oberen Atemwege des Pferdes unter Belastung.

Schlüsselwörter: Pferd, Endoskopie, Obere Luftwege, Laufband, Belastung

\section{Introduction}

The use of treadmills in equine research and training is not new. Horses were exercised on mechanical tread- mills during the long sailboat trips from Europe to North America. In the latter part of the 19th century Hagemann 
and Zuntz already used a steam driven treadmill to investigate the oxygen consumption of working draught horses. The first modern, motor driven treadmill in equine research was used at the Royal Swedish Veterinary School in Stockholm during the 1960s. But the evaluation of upper respiratory tract dysfunctions in horses during exercise on high-speed treadmills is a relatively new method (Derksen et al., 1986; Stick and Derksen, 1989; Belknap et al., 1990; Morris and Seeherman, 1990). Its importance lies in the fact that many functional disorders (i.e. dorsal displacement of the soft palate, pharyngeal collapse) are not apparent at rest. On the other hand abnormal findings at rest do not necessarily mean a functional limitation during exercise (Williams et al., 1990, Morris and Seeherman, 1991). In additon, some methods are not sensitive enough to diagnose mild disease stages at rest.

There are different methods of assessing upper respiratory function in horses during exercise. These include endoscopy, upper airway pressure measurement and airflow measurement (pneumotachography). Recently there have been many advances in the techniques and the knowledge about the diagnostic value of these tests. The purpose of this review is to describe the techniques of the evaluation of the upper respiratory tract in the horse during exercise, list the indications, and discuss the usefulness and value of the different methods. Part I of the review deals with endoscopy during exercise.

\section{Material and Methods (Literature Reviewed)}

Publications on the evaluation of the upper respiratory tract function during exercise were found by consulting two databases. The Index Medicus (Medline) and the Commonwealth Agricultural Bureaux (CAB) were searched for the terms "horse" or "equine" and "treadmill". Reports pertaining to the upper respiratory tract were then selected' manually. The search was carried out for the period from 1966 to the current date. Articles in the Proceedings of the American Association of Equine Practitioners, the American College of Veterinary Internal Medicine, the American College of Veterinary Surgeons and the Proceedings of the Geneva Congress of Equine Medicine and Surgery were included as original, if the methods were clearly stated. This review encompasses all the original articles and reviews on the evaluation of the equine upper respiratory tract on a treadmill found by the above stated searching method. In addition selected references on basic principles of different measurement techniques and specific airway disorders are included.

\section{Results}

Ventilation seems to be an important limiting factor of performance in strenuously exercising horses (Petsche et al., 1995). In addition, respiratory tract disorders are the second most cause for poor performance in horses (Morris and Seeherman, 1991). The introduction of the flexible fiberoptic endoscope in equine medicine has been helpful in the description and diagnosis of several upper respiratory tract disorders (Cook, 1974, 1981a, 1981b; Raphel, 1982). Recognized causes of upper airway obstruction at rest are laryngeal hemiplegia $(\mathrm{LH})$, dorsal displacement of the soft palate (DDSP), epiglottic entrapment (EE), arytenoid chondropathy, rostral displacement of the palatopharyngeal arch, subepiglottic cysts, and pharyngeal cicatrices (Cook, 1974, 1981a, 1981b; Raphel, 1982; Lumsden et al., 1995). During exercise large pressure changes occur in the upper respiratory tract (Derksen et al., 1986). Studies of upper airway flow mechanics in exercising horses have made it clear that identification of an upper airway function abnormality does not necessarily mean a functional airway obstruction when the horse is exercising (Stick and Derksen,1989; Williams et al., 1990). On the other hand, the abscence of an upper airway abnormality at rest does not rule out a functional obstruction during strenous exercise (Morris and Seeherman, 1990). Attempts to mimic airflows and pressure changes during exercise include endoscopy immediately after exercise, during nasal occlusion (Holcombe et al., 1996) and chemically induced hyperventilation with doxapram [Dopram $\Theta$ ] (Archer et al., 1991) or lobelinum hydrochloride [Lobelin $\circledast$ ] (Art et al., 1991; Reutter, 1993).

\section{The Treadmill}

Until the late 1980s most treadmills only reached speeds of 3 to $6 \mathrm{~m} / \mathrm{s}$ and therefore could only be used for studying horses during low intensity exercise. On the modern high-speed treadmills horses can be tested at high intensity exersice at speeds up to $18 \mathrm{~m} / \mathrm{s}$ which is necessary for the assessment of upper airway function. Treadmills used for clinical exercise testing should have sufficient tread length and width. This requires a length of at least 3.4 meters and a width of at least 0.8 meters (Rose and King, 1993). Optimal is a length of 4 to 5 meters and a width of 1 to 1.5 meters (Seeherman, 1991). The additional length and width gives the horse sufficient room for momentary changes in position on the belt without excessive contact with the side rails or premature termination of the exercise test in case the horse is carried back. For exercise at high speed it is also important to have saftey devices as an emergency stop and a gantry with a safety belt.

Most of the commercially available large motorized treadmills meet these criteria : Mustang 2200 (Kagra AG, Fahrwangen, Switzerland); Säto II (Uppsala, Sweden; Equispeed Technologies, Raymore, Missouri, USA); Classic Walmanik (Walmanik International Corp., Freedom PA, USA). An extensive description of dimensions and housing conditions for treadmill installations is given elsewhere (Seeherman, 1991; Seeherman et al., 1992). 
Methodology of the Evaluation of the Upper Airways during Treadmill Exercise

\section{Preexamination}

A complete history and physical examination with emphasis on the respiratory tract always precedes examination during strenous exercise. (Morris, 1991). This will include external palpation of the laryngeal and pharyngeal area to identify any swelling or atrophy of the cricoarytenoideus dorsalis muscle, and a standing endoscopic evaluation of the respiratory tract including the cervico-laryngeal reflex (slap-test) (Greet et al., 1980). Endoscopy at rest should be attempted without sedation, because it is reported that xylazine alters the arytenoid abduction (Archer et al., 1991, Valdes-Vasquez et al., 1997). If indicated such as with suspected arytenoid chondritis, pharyngeal abscessation, DDSP and guttural pouch infection radiographs can be taken. Any abnormalities should be recorded to be able to compare it with observed dysfunction during exercise.

In addition, a thorough lameness examination should precede treadmill exercise to rule out an orthopedic problem as a cause of poor performance and to ensure that the horse is able to work on a treadmill at high speeds without being harmed.

\section{Indications}

An overview of indications for exercise endoscopy is given in Table1.

Tab. 1: Indications for exercise endoscopy. Indikationen der Belastungsendoskopie.

\begin{tabular}{|l|l|l|}
\hline History & $\begin{array}{l}\text { Endoscopy } \\
\text { at rest }\end{array}$ & $\begin{array}{l}\text { Endoscopy } \\
\text { during exercise }\end{array}$ \\
\hline \hline Abnormal inspiratory & LH grade II & $\begin{array}{l}\text { Indicated in } \\
\text { connection with PP } \\
\text { Indicated } \\
\text { Not necessary }\end{array}$ \\
\hline $\begin{array}{l}\text { Abnormal inspiratory } \\
\text { and/or expiratory } \\
\text { noise with/without PP }\end{array}$ & $\begin{array}{l}\text { Ulceration or } \\
\text { LHemorrhage of any } \\
\text { structure of the } \\
\text { larynx or pharynx }\end{array}$ & Indicated \\
\hline $\begin{array}{l}\text { Abnormal respiratory } \\
\text { noises with/without PP }\end{array}$ & No abnormalities & Indicated \\
\hline $\begin{array}{l}\text { PP of unknown origin } \\
\text { musculoskeletal ab- } \\
\text { normalities excluded) }\end{array}$ & No abnormalities & Indicated \\
\hline $\begin{array}{l}\text { After surgical correction } \\
\text { of upper airway dis- } \\
\text { orders especially if no } \\
\text { improvment of respirato- } \\
\text { ry noise or performance } \\
\text { is observed }\end{array}$ & Inconclusive findings & Indicated \\
\hline
\end{tabular}

$\mathrm{LH}=$ laryngeal hemiplegia; $\mathrm{PP}=$ poor performance

\section{Dorsal Displacement of the Soft Palate (DDSP)}

Recent studies by Derksen and Coworkers (1997) indicate that DDSP might be caused by damage to the pharyngeal branches of the vagal nerve which travel with the pharyngeal plexus close to the retropharyngeal lymphnodes. DDSP causes clinical signs during strenous exercise but not at rest. The displacement can be associated with an inspiratory and expiratory or mainly expiratory noise and often a sudden slowing down of the horses during exercise. Certain endoscopic observations at rest are suggestive for the presence of intermittent DDSP. DDSP is easily induced by nasal occlusion or withdrawal of the endoscope from the trachea. Normally the soft palate is returned into the normal position after swallowing. Persistence of the induced displacement over repeated swallowing manoeuvers, mucosal ulceration or bleeding of the free border of the soft palate, the dorsal pharynx or the tip of the epiglottis, and a small or flaccid appearing epiglottis are suggestive for intermittent DDSP (Morris ,1991; Lumsden et al., 1995; Kannegieter and Dore, 1995). However, there are also horses with intermittent DDSP which do not show any signs at resting endoscopy (Lumsden et al., 1995; Kannegieter and Dore, 1995).

\section{Laryngeal Hemiplegia (LH)}

$\mathrm{LH}$ describes asynchronous, asymmetric arytenoid cartilage movement caused by degeneration or damage most times of the left recurrent nerve. For the description of the various degrees of asynchronous/asymmetric movement of the arytenoid cartilages at rest different grading systems have been developed (Baker, 1983; Rakestraw et al., 1991; Lane, 1993). This review will use the grading system by Rakestraw and Coworkers (1991) (Table 2).

Tab. 2: Subjective Laryngeal Grades for Resting Horses (Rakestraw et al., 1991).

Einteilung der Kehlkopffunktion am stehenden Pferd (Rakestraw et al., 1991).

\begin{tabular}{|cl|}
\hline Grade & \multicolumn{1}{|c|}{ Movement } \\
\hline \hline I & $\begin{array}{l}\text { Symmetrical, synchronous abduction and adduction } \\
\text { of the left and right arytenoid cartilages. }\end{array}$ \\
\hline II & $\begin{array}{l}\text { Some asynchronous movement (hesitation, flutter, or } \\
\text { abductor weakness) of the left arytenoid cartilage du- } \\
\text { ring any phase of respiration. Full abduction of the left } \\
\text { arytenoid cartilage can be maintained by swallowing } \\
\text { or nasal occlusion. }\end{array}$ \\
\hline III & $\begin{array}{l}\text { Asynchronous movement (hesitation, flutter, or ab- } \\
\text { ductor weakness) of the left arytenoid cartilage during } \\
\text { any phase of respiration. Full abduction of the left } \\
\text { arytenoid cartilage cannot be induced and maintained } \\
\text { by swallowing or nasal occlusion. }\end{array}$ \\
\hline IV & $\begin{array}{l}\text { There is no substantial movement of the left arytenoid } \\
\text { cartilage during any phase of respiration. }\end{array}$ \\
\hline
\end{tabular}


$\mathrm{LH}$ is associated with an inspiratory stertor during exercise. A clinical examination should include exercise with the horse in normal head position during performance and endoscopic evaluation of the arytenoid excursions during nasal occlusion, during and after an induced swallowing reflex or during induced hyperventilation by Lobelin ${ }^{\circledR}$ (Reutter, 1993). Morris and Seeherman (1990) and Kannegieter and Dore (1995) discuss the possibility of a progressive dynamic collapse with extented exercise in horses with laryngeal function grade I and II. But an extensive study comparing arytenoid cartilage movement at rest and during exercise has shown that horses with laryngeal function grade I and II were all able to fully abduct the arytenoid cartilages during exercise (Rakestraw et al., 1991). Also Lumsden and coworkers (1995) do not consider laryngeal function grade I and II an indication for evaluation on the treadmill. LH grade III seems to be the laryngeal function in question. There are different studies which suggest that between 20 and $70 \%$ of horses with laryngeal function grade III at rest experience a pronounced central displacement of the left arytenoid cartilage ("dynamic collapse") and occasional collapse of the rima glottidis during exercise (Rakestraw et al., 1991, Lumsden, et al., 1995). Based on calculated left to right ratios during exercise racehorses with resting $\mathrm{LH}$ grade III were divided into 3 subgroups: IIIA-the horse is able to obtain and maintain full abduction of both arytenoids during exercise [maximal abduction ratio of 0.80 , maximal collapse ratio of 0.79$]$, IIIB-the affected arytenoid is incompletely abducted, but this degree of abduction is maintained during exercise [maximal abduction ratio of 0.69 , maximal collapse ratio of 0.57 ] and IIIC-progressive and severe collapse of the affected arytenoid and the vocal cords [maximal abduction ratio of 0.61 , maximal collapse ratio of 0.18] (Hammer et al., 1995) suggesting that horses with grade IIIA do not require surgical intervention because they are able to maintain full abduction during exercise. However, approximately 95\% of the horses with LH grade III fall into category IIIB and IIIC. The same studies have shown that laryngeal function grade IV at rest make an evaluation during exercise unnecessary because of total paralysis of the arytenoid cartilage (Morris and Seeherman, 1990, 1991, Rakestraw et al., 1991, Lumsden et al., 1995).

\section{Epiglottic Entrapment (EE)}

EE presents mainly as a permanent disorder. It is defined as permanent when it is observed throughout the endoscopic examination, during swallowing and when observed on consecutive examinations at rest (Lumsden et al., 1995). Evaluation of persistent EE on the treadmill seems to be warranted to document the severity of airway obstruction, because airway pressure measurements have indicated that thick membranes (aryepiglottic fold) might cause a more severe airway obstruction than thin membranes (Williams et al., 1990). Intermittent EE has first been diagnosed during treadmill exercise endoscopy (Morris and Seeherman, 1991). Horses with intermittent EE do not have abnor- malities at rest (Weishaupt et al., 1998) and do not necessarily have a respiratory stertor (Lumsden et al., 1995).

\section{Other Indications}

Treadmill endoscopy has allowed the diagnosis of some rare functional disorders like epiglottic retroflexion (Parente et al., 1994; Lumsden et al., 1995; Derksen et al., 1997), vocal cord prolapse without additional arytenoid cartilage dysfunctions (Hackett, et al., 1994; Kannegieter and Dore, 1995) and collapse of the pharynx (Strand and Staempfli, 1993; Hackett, et al., 1994) which were not apparent at resting endoscopy. Currently there is no knowledge about the clinical significance of these rare disorders.

Evaluation of the upper respiratory tract during treadmill exercise can also be indicated after surgical correction of upper airway disorders (Stick and Derksen, 1989; Kannegieter and Dore, 1995) to control the result, especially if there is no improvement in performance or respiratory stertor.

\section{Treadmill Accommodation and Exercise Protocols}

Protocols for the dynamic evaluation of the upper airway function should simulate a horse's usual performance conditions as close as possible (Morris and Seeherman, 1990). During the examination the horse should wear its own tack as bridle, bit, hobbles or overcheck. Side reins can be used if it is necessary to achieve a flexed head and neck position during performance (Lumsden et al., 1995). Before examination during exercise the horse has to be familiarized with the treadmill. There are different protocols used for acclimatization of the horse to run comfortably on a treadmill. Morris and Seeherman (1990) use a protocol that is designed to minimize disruption of the training schedule. The whole evaluation of the respiratory tract, including two resting endoscopies can be performed in $11 / 2$ to 2 hours. These authors report that it takes typically only 20 to $30 \mathrm{mi}-$ nutes to get the horses (Thoroughbreds, Standardbreds) running on the treadmill at high speeds. The group at Michigan State University (Stick et al., 1991; Derksen, 1993; Lumsden et al., 1995) use a protocol that will take 2 or 3 days for traininig and endoscopy. The horse has two training runs which can be performed in one or two days. Other investigators report on average one to two training runs to acclimatize the horses to the treadmill (Strand and Staempfli, 1993; Kannegieter and Dore, 1995). Horses not trained for high performance running (Warmbloods, draught horses, ponies) tend to need a longer accomodation time for exercising at gallop speeds needed for the upper respiratory tract evaluation than Thoroughbreds and Standardbreds (personal observation).

During exercise on the treadmill the horse is encouraged to maintain its position on the treadmill. The speed is adjusted to accomodate the use and fitness level of the horse. Prior to the evaluation the horse has a warm up period. Pub- 
lished protocols use $4.5 \mathrm{~m} / \mathrm{s}$ for 6 minutes trotting (Morris and Seeherman, 1990) or 5-7 m/s for 5 minutes and 12-14 $\mathrm{m} / \mathrm{s}$ for 1 minute at the gallop (Stick et al. 1991; Derksen, 1993; Lumsden et al., 1995). The treadmill is usually inclined at 3\% for trotting horses (Standardbreds) and at $6 \%$ for galloping horses (Thoroughbreds, endurance horses and 3 day eventers) (Morris, 1991). Parente and Martin (1995) use three degrees of inclination for Thoroughbreds and no inclination for Standardbreds. In human exercise physiology as well as in equine sports medicine it is well known that exercise on a treadmill at level causes less energy expenditure than exercise on the track (Barrey et al., 1993). The same authors determined $1.7-2.1$ degrees as the optimal inclination for saddle horses (3 day eventers) to get the same heart rate response on the treadmill at certain speeds as during exercise over ground. The inclination is necessary to obtain the same workload than over ground, to simulate the load of the rider or the sulky (Morris, 1991). In addition, the inclination makes exercise on the treadmill safer, because lower speeds can be used. The lower inclination for Standardbreds is necessary to enable these horses to maintain stride (Morris, 1991). Early protocols measured the horses during submaximal exercise (Shappell et al., 1988). Results indicated that the evaluation methods are more sensitive near maximal exercise (Lumsden et al., 1994) and that the fastest possible speed for the individual horse are necessary to reproduce a similar stress on the upper respiratory tract as under competiton conditions (Ducharme et al., 1994). The individual horses maximal heart rate is determined by an incremental exercise test. Then the horses are tested at the treadmill speed corresponding to their $75 \%$ of maximal heart rate (HR75 max) and at maximal heart rate $\left(\mathrm{HR}_{\max }\right)$ for 2 minutes (Lumsden et al., 1994). Often several trials are necessary to fatigue the horse and induce certain dysfunctions.

\section{Endoscopy Technique}

The first reports on the use of endoscopy during exercise on a high-speed treadmill were published in 1988 (Morris and Seeherman) and 1989 (Stick and Derksen). Although it is possible to use a fiberoptic endoscope, the advent of videoendoscopes in veterinary medicine made it possible to obtain clearer images during exercise, because they have better luminous intensity than fiberoptic endoscopes and can be equipped with electronic shutters [i.e. Videoendoscope CF 100 HL, Olympus; Video Gastroscope for Horses, Karl Storz $\mathrm{GmbH}$. An endoscope length of $180 \mathrm{~cm}$ is desirable to be able to fix it properly to the bridle and have enough length available to correct for momentary position changes of the horse during exercise.

After the warm-up period the treadmill is stopped and an endoscope is inserted after superficial anesthesia with $2 \%$ lidocain into the ventral meatus of the right or left nostril and positioned to allow visualization of the pharynx and larynx without touching any of the laryngeal structures. The endoscope is fastened to the bridle by adhesive tape (Fig. 1), penrose drains or Velcrr® straps (Morris, 1991; Stick et al. 1991; Derksen, 1993). The Velcro® straps allow a quick removal of the device in case of an accident or uncooperative horse (Morris, 1991). To allow easy visualization, as well as permanent recording the endoscope is coupled with a videotape recorder (Morris and Seeherman, 1990). Additionally a microphone can be attached to the endoscope 5 to $10 \mathrm{~cm}$ from the nostrils to allow recording of the abnormal respiratory noises (Morris and Seeherman, 1990). A minimum of three (Lumsden et al., 1995) to four (personal observation) handlers is needed to safely perform an endoscopy at speed. One person has to adjust the monitorimage continously. Two/three other operators handle the horse and operate the treadmill. After insertion of the endoscope the treadmill is started again and the exercise protocol completed (Stick et al. 1991, Derksen, 1993, Lumsden et al., 1995). Treadmill speed and inclination are adapted to the horse's fitness level or horses are exercised at their usual racing gait $(9 \mathrm{~m} / \mathrm{s}$ to $13.5 \mathrm{~m} / \mathrm{s})$ to reach a heart rate in excess of 220 beats/minute (Morris and Seeherman, 1990; Morris, 1991; Parente and Martin, 1995). It has been observed that disturbing the horse by sudden slowing down can help to induce the displacement of the soft palate (Lumsden et al., 1995).

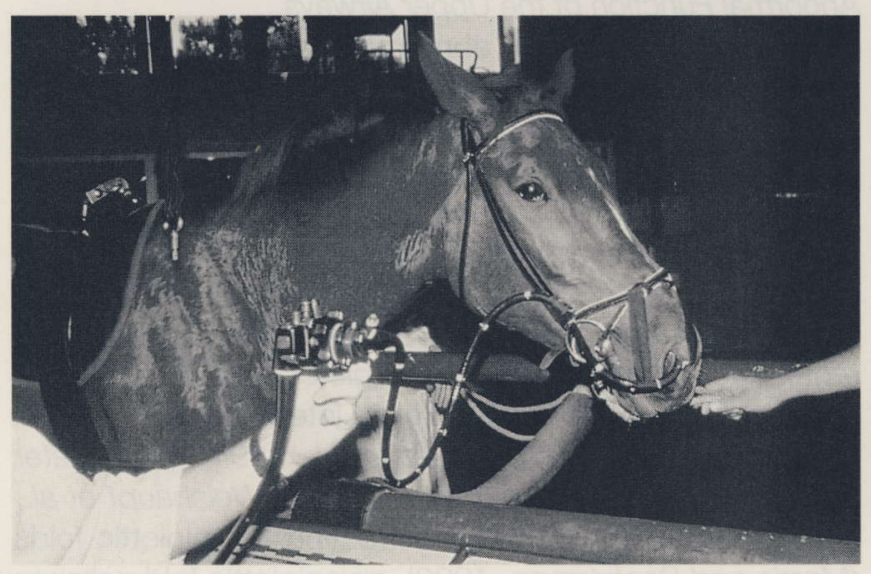

Fig. 1: Horse prepared for exercise endoscopy on a treadmill. The endoscope is fixed to the bridle with adhesive tape.

Für eine Belastungsendoskopie vorbereitetes Pferd. Das Endoskop ist mit Klebeband am Zaum fixiert.

30 minutes after exercise a second endoscopy at rest is performed (Morris, 1991; Lumsden et al., 1995). Afterwards the video recording is evaluated in slow motion or freeze frame mode, sequence by sequence.

\section{Observations during Exercise}

\section{Normal Function of the Upper Airways}

In the resting horse the arytenoid cartilages are slightly adducted during expiration and slightly abducted during inspiration. The swallow reflex includes the complete adduction of the laryngeal cartilages, dorsal displacement of the epiglottis and ventral movement of the roof of the pharynx and dorsal movement of the soft palate (closure of the 
nasopharyngeal sphincter) to prevent the passage of food or saliva into the trachea. This is followed by complete, bilateral abduction of the arytenoid cartilages. Then the cartilages return into resting position (Morris, 1991). Displacement of the soft palate can be induced in normal horses by insertion of the endoscope into the trachea and withdrawing it again or by touching the laryngeal structures. The displacement than occurs after a swallowing reflex. 'Normal' horses return the soft palate into normal position after an other swallowing reflex (Morris, 1991).

During a transitional time at the beginning of exercise frequent full symmetrical abduction and adduction of the arytenoid cartilages can be observed before full abduction is achieved (personal observation). During exercise the 'normal' horse fully abducts the arytenoid cartilages as ventilation increases (Morris, 1991). The larynx stays open during strenous exercise until ventilation returns to resting levels. The horse is able to swallow during strenuous exercise; the reflex is intact with full adduction of the arytenoid cartilages, which then return to the fully abducted position. Horses may swallow several times during exercise, but repeated swallowing indicates an irritation or hypersecretion as in COPD affected horses (Morris, 1991)

\section{Abnormal Function of the Upper Airways}

Obstructing functional abnormalities observed during exercise are intermittent DDSP (Morris and Seeherman; 1990; Stick et al., 1991; Parente et al., 1994; Hackett et al., 1994; Parente and Martin, 1995; Lumsden et al., 1995; Kannegieter and Dore, 1995) [Figs 2a-b], LH or dynamic arytenoid cartilage collapse (Morris and Seeherman, 1990; Stick et al., 1991; Morris and Seeherman, 1991; Rakestraw et al., 1991; Parente et al., 1994, Parente and Martin, 1995; Kannegieter and Dore, 1995; Lumsden et al., 1995) [Figs.2c-d], intermittent EE (Morris and Seeherman, 1991, Hackett et al., 1994; Kannegieter and Dore, 1995; Lumsden et al., 1995; Weishaupt et al., 1997), permanent EE with obstructing aryepiglottio folds (Morris and Seeherman, 1990), aryepiglottic fold collapse (Hackett et al., 1994; Kannegieter and Dore, 1995; Parente and Martin, 1995), aryepiglottic fold flutter (Kannegieter and Dore, 1995) vocal fold prolapse (Hackett et al., 1994; Lumsden et al., 1995), vocal cord flutter (Kannegieter and Dore, 1995), epiglottic retroversion (Parente and Martin, 1995; Derksen et al., 1997), epiglottic flutter (Kannegieter and Dore, 1995), collapse of the roof of the nasopharynx (Strand and Staempfli, 1993; Hackett et al., 1994), prolapse of the cranial part of the soft palate $(\mathrm{Hol}-$ combe et al., 1997), rostral displacement of the palatopharyngeal arch (Lumsden et al., 1995) and a combination of several disorders (Kannegieter and Dore, 1995; Lumsden et al., 1995). The most frequently observed dysfunctions are DDSP and LH with a range of 21 to 52 $\%$ and 9 to $25 \%$ of all upper airway obstructions, respectively (Stick et al., 1991; Morris and Seeherman, 1991; Rakestraw et al., 1991; Hackett, et al., 1994; Parente and Martin, 1995; Kannegieter and Dore, 1995; Lumsden et al., 1995). The incidence of functional upper airway obstruction in horses with a history of poor performance of unknown origin is reported to be between $17.7 \%$ and $26 \%$ (Morris and Seeherman; 1990, Morris and Seeherman, 1991; Parente and Martin, 1995; Kannegieter and Dore, 1995; Lumsden et al., 1995). Horses with a history of poor performance and an abnormal respiratory noise and/or suggestive endoscopy at rest had an incidence of upper airway obstruction between $32 \%$ and 92 \% (Stick et al., 1991; Morris and Seeherman, 1991; Hackett, et al., 1994; Kannegieter and Dore, 1995). Lumsden and coworkers (1995) reported that 28 of $46(61 \%)$ horses with upper airway obstruction during exercise also had abnormalities at rest. This supports the importance of a careful clinical examination and endoscopy at rest before evaluation during exercise to increase the predicitive value of endoscopy during treadmill exercise.

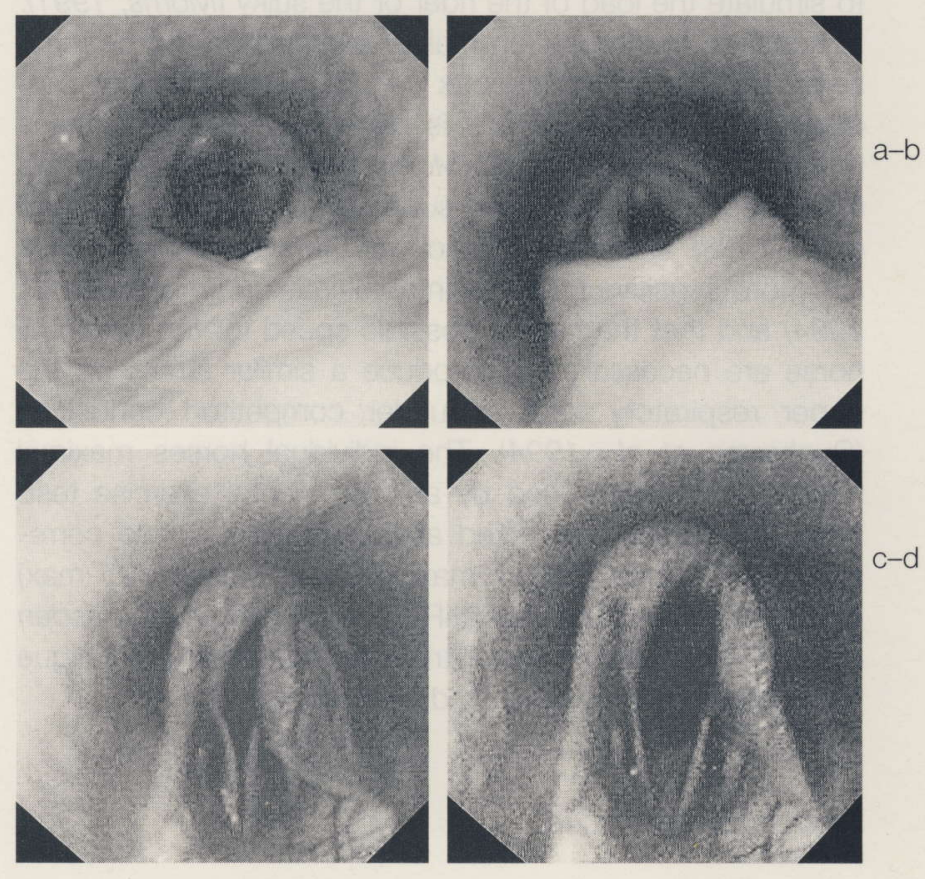

Fig. 2: Most frequently observed upper airway disorders during exercise endoscopy.

a) dorsal displacement of the soft palate during inspiration.

b) dorsal displacement of the soft palate during expiration with vibration of the free margin and bulging of the soft palate.

c) laryngeal hemiplegia grade IIIC during inspiration with severe prolapse of the left vocal cord and collapse of the left arytenoid cartilage.

d) laryngeal hemiplegia grade IIIC during expiration.

Am häufigsten beobachtete Veränderungen der oberen Atemwege während einer Belastungsendoskopie.

a) Dorsalverlagerung des weichen Gaumens während der Inspiration.

b) Dorsalverlagerung des weichen Gaumens während der Exspiration mit Vibration des freien Randes und Aufwölbung des weichen Gaumens.

c) Hemiplegia laryngis Grad IIIC während der Inspiration mit hochgradigem Vorfall des linken Stimmbandes und Kollaps des linken Aryknorpels.

d) Hemiplegia laryngis Grad IIIC während der Exspiration. 
The limitation of endoscopy during exercise is that it requires subjective interpretation of airway function. Upper airway function can be evaluated objectively by quantitative methods like upper airway pressure and airflow measurements (pneumotachography).

In conclusion, examination of the upper respiratory tract during exercise on high-speed treadmills can be a useful tool in evaluation of upper respiratory tract disorders. It has been shown that many functional disorders only occur during high intensity exercise. On the other hand some abnormalities observed at rest do not produce a functional disorder during exercise. But the evaluation on the treadmill should not be used as a routine diagnostic tool. A good history, careful physical examination and endoscopic examination at rest are prerequisites before dynamic evaluation can be indicated. Many horses with a functional upper airway obstruction during exercise have a history of an abnormal respiratory noise during exercise or suggestive diagnostic findings at examination at rest. Videoendoscopy during treadmill exercise as a subjective technique already can accomplish a good evaluation of the upper airway function. But a final diagnosis of the presence of a respiratory limitation can only be made by quantitative measurement of respiratory mechanics (airway pressure and flow-volume measurement). Videoendoscopy coupled with these objective methods is currently considered the optimum method to evaluate upper airway function.

\section{Literature}

Archer, R.M., Lindsay, W.A. and Duncan, I.D. (1991): A comparison of techniques to enhance the evaluation of equine laryngeal function. Equine vet. J. 23, 104-107.

Art, Tatjana., Desmecht, D., Amory, H. and Lekeux, P. (1991): Lobeline-induced hyperpnea in Equids. J.Vet. Med. A 38

Baker, G.J. (1983): Laryngeal asynchrony in the horse: Definition and significance. In: Equine exercise physiology. Eds.: Snow, D.H.; Person, S.G.B; Rose, R.J.. Cambridge, Granta, 46-50.

Barrey, E. Galloux, P., Valette, J.P., Auvinet, B. and Wolter, R. (1993): Determination of the optimal treadmill slope for reproducing the same cardiac response in saddle horses as overground exercise conditions. Vet. Rec. 133, 183-185.

Belknap, J.K., Derksen, F.J. Nickels, F.A. and Stick, J.A. (1990): Failure of subtotal arytenoidectomy to improve upper airway flow mechanics in exercising Standardbreds with induced laryngeal hemiplegia. Am. J. Vet. Res. 51, 1481-1487.

Cook, W.R. (1974): Some observations on diseases of the ear, nose and throat in the horse, and endoscopy using a flexible fiberoptic endoscope. Vet. Rec. 94, 533-541.

Cook, W.R. (1981a): Some observations on form and function of the equine upper airway in health and disease. I. . The pharynx. Proceedings Am. Assoc. Equine Pract. 27, 355-391.

Cook, W.R. (1981b): Some observations on form and function of the equine upper airway in health and disease. II. . The larynx. Proceedings Am. Assoc. Equine Pract. 27, 393-451.

Derksen, FJ., Stick, J.A. Scott, E. A., Robinson, E.A., and Slocombe, R.F. (1986): Effect of laryngeal hemiplegia and laryngoplastic on air-

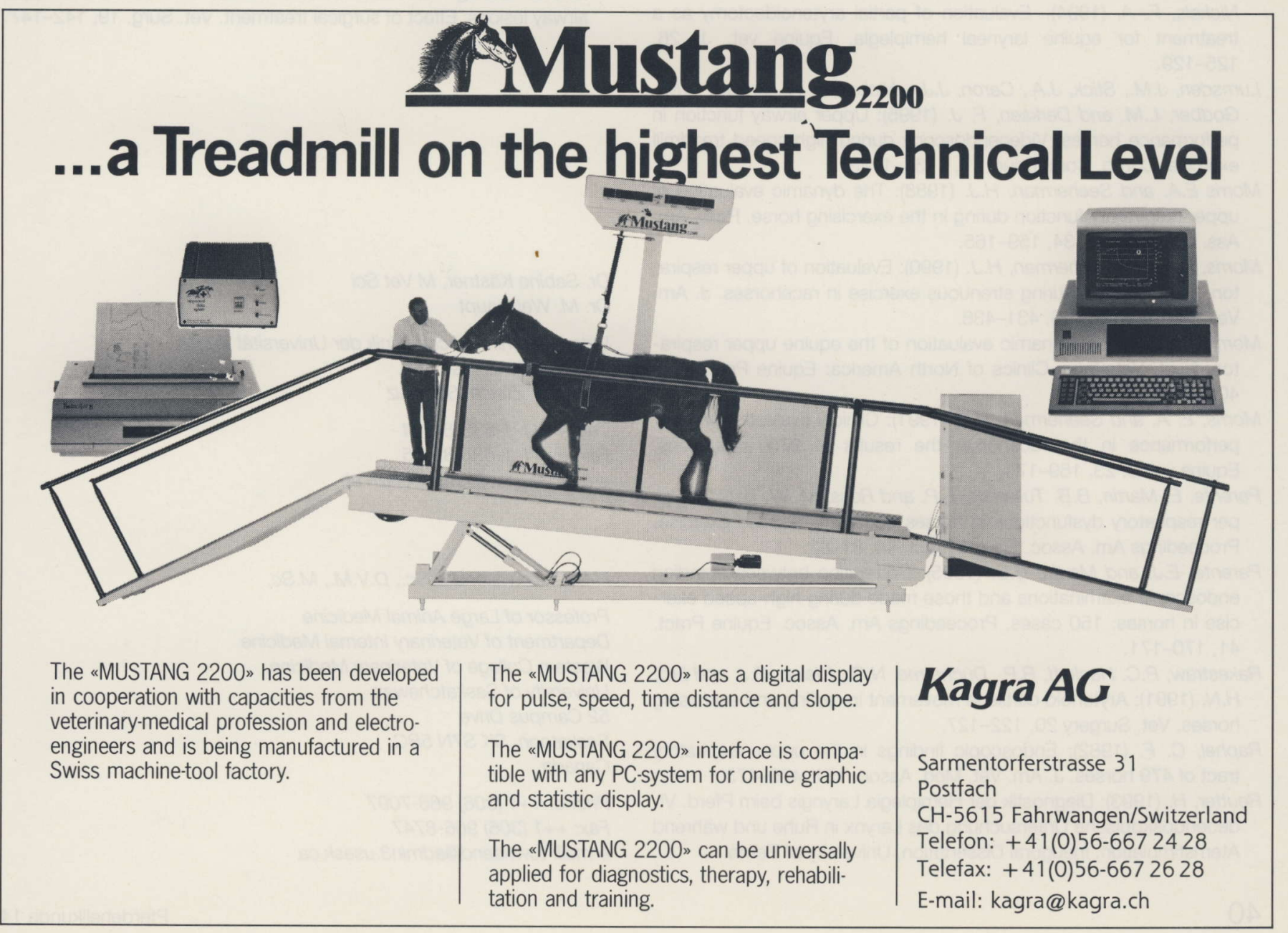


way flow mechanics in exercising horses. Am. J. Vet. Res.47, 16-20.

Derksen, F.J. (1993): Upper airway evaluation of horses during treadmill exercise. Proceedings 11 th ACVIM Forum, 607-609.

Derksen, F.J. Holcombe, S.J. and Stick, J.A. (1997): Applied physiology of the upper airway. In: Proceedings of the 1997 Dubai International Equine Symposium Eds: N.W. Rantanen and M.L. Hauser, Matthew R. Rantanen Design, 23-35.

Greet, T.R.C., Jeffcott, L.B., Whitwell, K.E. and Cook, W.R. (1980): The slap test for laryngeal adductory function in horses with suspected cervical spinal cord damage. Equine Vet. J. 12, 127

Hackett, R.P., Ducharme, N.G. and Mitchell, L. (1994): The role of treadmill endoscopy in diagnosis of dynamic obstruction of the upper airway. Proceedings Am. Assoc. Equine Pract 40, 83.

Hammer, E.J., Tulleners, E.P., Parente, E.J., and Martin, B.B. (1995): High-speed treadmill evaluation and management of 26 racehorses with grade III left laryngeal hemiparesis, in Abstracts Am. Coll. Vet. Sur. Symposium.

Holcombe, S.J., Derksen, J.F., Stick, J.A., Robinson N.E. and Boehler, D.A. (1996): Effect of nasal occlusion on tracheal and pharyngeal presssures in horses. Am. J. Vet. Res. 57. 1258-1260.

Holcombe, S.J., Derksen, F.J., Stick, J.A. and Robinson, N.E. (1997): Effect of bilateral tenectomy of the tensor veli palatini muscle on soft palate function in horses. Am. J. Vet. Res. 58, 317-321.

Kannegieter, N.J. and Dore, M.L. (1995): Endoscopy of the upper respiratory tract during treadmill exercise: a clinical study of 100 horses. Aus. Vet. J. 72, 101-107.

Lane, J.G. (1993): Proceedings 15th Bain Fallon Lectures, Australian Veterinary Association, Artarmon, 173.

Lumsden, J.M., Derksen, F.J. Stick, J.A. and Robinson, N.E. (1993): Use of flow-volume loops to evaluate upper airway obstruction in exercising Standardbreds. Am. J. Vet. Res. 54, 766-775.

Lumsden, J.M., Derksen, F.J., Stick, J.A., Robinson, N.E. and Nickels, F. A. (1994): Evaluation of partial arytenoidectomy as a treatment for equine laryneal hemiplegia. Equine vet. J. 26, 125-129.

Lumsden, J.M., Stick, J.A., Caron, J.J., Nickels, F. A., Brown, C.M., Godber, L.M. and Derksen, F. J. (1995): Upper airway function in performance horses: Videoendoscopy during high-speed treadmill exercise. Comp. Cont. Educ. 17, 1134-1143.

Morris E.A. and Seeherman, H.J. (1988): The dynamic evaluation of upper respiratory function during in the exercising horse. Proc. Am. Ass. equine Pract. 34, 159-165.

Morris, E.A. and Seeherman, H.J. (1990): Evaluation of upper réspiratory tract function during strenuous exercise in racehorses. J. Am. Vet. Med. Assoc. 196, 431-438.

Morris, E. A. (1991): Dynamic evaluation of the equine upper respiratory tract. Veterinary Clinics of North America: Equine Practice 7 , 403-416.

Morris, E. A. and Seeherman, H.J. (1991): Clinical evaluation of poor performance in the racehorse: the results of 275 evaluations. Equine vet. J. 23, 169-174.

Parente, E. Martin, B.B. Tulleners, E.P. and Ross, M. W. (1994):. Upper respiratory dysfunctions in horses during high-speed exercise. Proceedings Am. Assoc. Equine Pract. 40, 81-82.

Parente, E.J. and Martin, B.B. (1995): Correlation between standing endoscopic examinations and those made during high-speed exercise in horses: 150 cases. Proceedings Am. Assoc. Equine Pract. 41, 170-171.

Rakestraw, P.C. Hackett, R.P., Ducharme, N.G., Nielan, G.J. and Erb, H.N. (1991): Arytenoid cartilage movement in resting and exercising horses. Vet. Surgery 20, 122-127.

Raphel, C. F. (1982): Endoscopic findings in the upper respiratory tract of 479 horses. J. Am. Vet. Med. Assoc. 181, 470-473.

Reutter, H. (1993): Diagnostik der Hemiplegia Laryngis beim Pferd. Videoendoskopische Untersuchung des Larynx in Ruhe und während Atemstimulation. Inaugural Dissertation, University of Berne.
Rose, R.J. and King, C.M. (1993): Use of treadmills in equine practice. Comp. Cont. Educ. 15, 875-878.

Seeherman, H. J. (1991): Treadmill exercise testing. Treadmill installation and training protocols used for clinical evaluations of equine athletes. Vet. Clin. North America: Equine Practice 7, 259-269.

Seeherman, H.J., Morris, E. and O'Callaghan, M.W. (1992): Sports Medicine-Evaluation of equine athletic performance-Evaluation techniques. In: Equine Surgery Ed: Auer, J.A., W.B. Saunders, Philadelphia, 1106-1132.

Shappell, K.K., Derksen, F.J., Stick, J.A. and Robinson, N.E. (1988): Effects of ventriculectomy, prosthetic laryngoplasty, and exercise on upper airway function in horses with induced left laryngeal hemiplegia. Am. J. Vet. Res. 49, 1760-1765.

Stick, J.A. and Derksen, F.J. (1989): Use of videoendoscopy during exercise for determination of appropriate surgical treatment of laryngeal hemiplegia in a colt. J. Am. Vet. Med. Assoc 195, 619-622.

Stick, J.A., Derksen, F. J., Nickels, F.A., Brown, C.M., Arden, W. A. and Fulton, I. C. (1991): Upper airway videoendoscopy during exercise in poorly performing horses. Proceedings Am. Assoc. Equine Pract.36, 431-438.

Strand, E. and Staempfli, H. R. (1993): Dynamic collapse of the roof of the nasopharynx as a cause of poor performance in a Standardbred colt. Equine vet. J. 25, 252-254.

Valdes-Vasquez,M.A., Aguilera-Tejero, E. and Mayer-Valor, R. (1997): Effects of xylazine during endoscopic evaluation on functional upper respiratory disorders in horses ECVS Proceedings 6, 111-112.

Weishaupt, M. A., Kästner, S.B.R., Feige, K. Schmid, M. and Auer, J.A. (1998): Airflow characteristics and alteration of stride-respiration coupling in a Trakehner Stallion with intermittent epiglottic entrapment. Equine vet. Educ. in press

Williams, J.W. , Meagher, D.M. Pascoe, J.R. (1990): Upper airway function during maximal exercise in horses with obstructive upper airway lesions: Effect of surgical treatment. Vet. Surg. 19, 142-147.

Dr. Sabine Kästner, M Vet Sci

Dr. M. Weishaupt

Veterinär-Chirurgische Klinik der Universität Zürich

Winterthurerstrasse 260

CH-8057 Zürich, Schweiz

Tel.: ++41-1-635-84-34

Fax: ++41-1-635-89-05

e-mail: skaest@vetchir.unizh.ch

H.G.G. Townsend B.Sc., D.V.M., M.Sc.

Professor of Large Animal Medicine

Department of Veterinary Internal Medicine

Western College of Veterinary Medicine,

University of Saskatchewan

52 Campus Drive

Saskatoon, SK S7N 5BC,

Canada

Phone: ++1 (306) 966-7097

Fax: ++1 (306) 966-8747

e-mail: townsend@admin3.usask.ca 